\title{
Gore announces boost for neutron research at Oak Ridge lab
}

Washington. Al Gore, the US vice-president, brought some election-year largesse to his home state of Tennessee earlier this month when he announced that the Clinton administration is to ask Congress for $\mathbf{\$ 2 3}$ million for work on a new source of research neutrons at Oak Ridge National Laboratory (ORNL) in the fiscal year 1998 (which begins on 1 October 1997).

Gore, a former Tennessee senator, also announced during a campaign stop at Oak Ridge that the administration is to provide $\$ 10$ million to upgrade the High Flux Isotope Reactor (HFIR), the most intense source of neutrons available for research use in the United States.

Although he did not specify what the money would pay for, a Department of Energy (DoE) official said the department would continue funding the addition of a 'cold' neutron capability to the reactor, extending HFIR's neutron scattering capabilities.

ORNL officials remain confident that $D o E$ will fund the remainder of a $\$ 70$ million upgrade package they have proposed for the 30-year-old HFIR. Many of the improvements are designed to expand the reactor's capacity to produce radioisotopes.

The proposed \$1-billion new neutron spallation source planned for Oak Ridge replaces an earlier \$3-billion project to build what would have been the world's largest research reactor, which was cancelled last year in the face of tight budgets.

Bill Appleton, associate director of the laboratory, calls the announcement "a marvellous shot in the arm for the neutron community", saying that the laboratory considers it a commitment to proceed with construction of the new facility. But he acknowledges that the announced funding is considerably less than the $\$ 43$ million that ORNL considered necessary in fiscal year 1998 to proceed on the shortest possible timetable for completion.

According to Appleton, current efforts to complete a conceptual design are scheduled for completion during fiscal year 1997. At that point, assuming approval from Congress and then the president, the project would move into the detailed design phase.

Appleton argues that the US neutron research community has recognized the need for improved neutron-scattering capabilities since the 1970s, when newly built European reactors 'leapfrogged' US capabilities. Neutron scattering has "exploded" since HFIR was built in the 1960s. But Europe, with double the capability, has been able to meet the demands of university and industry researchers much more than the United States, he said.

\section{Biogeochemists and industry search for common interests}

London. Basic researchers in biogeochemistry from around the world last week joined representatives of industry and funding agencies to identify industrial and environmental problems that their research can help to solve.

"The reason for the meeting is the perception, common in many countries, of a change in scientific funding processes", with more emphasis on applications-oriented research, says Max Coleman, professor of sedimentology at the University of Reading, where the four-day event was held.

One of the aims of the meeting was to provide basic researchers with what Coleman describes as "the road map of success", reminding them that the new funding yardsticks of "wealth creation" and "quality of life" do not exclude basic research.

Industry was urged to outline what it wants from basic researchers. "Industry knows that basic research is its lifeblood", says Coleman but has been progressively reducing its research and development budget, which it increasingly considers the responsibility of governments. Yet governments were now more concerned with spending money on problem-solving research, such as Technology Foresight. Basic researchers had been caught in the middle, Coleman says, but would be mistaken to believe that they have lost out.

Delegates to the meeting included representatives from BP, the UK radioactive waste disposal agency NIREX, the US Department of Energy, the UK environment agency and various universities. It focused, in particular, on the potential applications of microbiology.

According to Phil Long, programme manager at the US Department of Energy

\author{
IMAGE \\ UNAVAILABLE \\ FOR COPYRIGHT \\ REASONS
}

Testing the ground: current priorities for funding need not rule out basic research.

Pacific Northwest National Laboratory, various conference working groups outlined a number of areas in which microbial processes could improve understanding of challenges, including underground radioactive waste disposal, oil and mineral exploration, water resources, contaminated land and even the origins of extraterrestrial life.

Frank Wobber, programme manager at the US Office of Energy Research and one of the speakers, says he sees no contradiction in the idea of setting priorities for basic research. Prioritization, he says, does not exclude the possibility of surprise results or "serendipity", which is sometimes described as the hallmark of basic research.

The idea that "it is a sin for basic research to help solve society's problems" needs to be dispelled, says Wobber. "What is wrong with a publicly funded basic researcher asking: is there a spin-off from what I am doing; is there a benefit?"' $\mathrm{He}$ also predicts that funds for "pure" basic research will be increasingly difficult to obtain without an applied dimension. "It is going to get harder and harder to say: 'I want to study bees' wings' without considering there is a huge honey industry out there." Ehsan Masood

\section{East Asian research universities explore links}

Tokyo. More than a dozen presidents of universities in Japan, the Chinese mainland, Taiwan, South Korea and Hong Kong met in Tokyo last week to discuss future activities of the recently formed Association of East Asian Research Universities, the first substantial attempt to link together universities in the region.

The association was launched earlier this year by Chia-Wei Woo, president of Hong Kong University of Science and Technology (HKUST). The original idea was to link together a small number of universities from East Asia with strong interests in science and technology, such as HKUST and South Korea's Pohang University of Science and Technology (POSTECH).

At the first meeting of nine presidents in Hong Kong, however, including those of
Tokyo University and Tsukuba University in Japan and Tsinghua (formerly spelt Qinghua) and Fudan universities of China, it was decided that the association could not be confined to science and technology, as these universities also have faculties in areas such as law and economics. It was therefore agreed that it should be an association of 'research' universities and so has rapidly expanded in size. Fourteen presidents met last week, and three more universities including Kyoto University of Japan and Taiwan University - are expected to join soon.

Nevertheless, the focus is still on science and technology. Last week, two task forces were set up. One will look into areas of possible collaboration in molecular biology and biotechnology. The other will investigate computer science. David Swinbanks 